\title{
Pathogenesis of cerebral malformations in human fetuses with meningomyelocele
}

\author{
Olga A de Wit ${ }^{1}$, Wilfred FA den Dunnen ${ }^{2}$, Krystyne M Sollie ${ }^{3}$, \\ Rosa Iris Muñoz ${ }^{4}$, Linda C Meiners ${ }^{5}$, Oebele F Brouwer ${ }^{1}$, \\ Esteban M Rodríguez ${ }^{4}$ and Deborah A Sival*6
}

\begin{abstract}
Address: ${ }^{1}$ Department of Neurology, University Medical Center, University of Groningen, Hanzeplein 1, 9700 RB, Groningen, The Netherlands, 2Department of Pathology and Laboratory Medicine, University Medical Center, University of Groningen, Hanzeplein 1, 9700 RB, Groningen, The Netherlands, ${ }^{3}$ Department of Obstetrics and Gynecology, University Medical Center, University of Groningen, Hanzeplein 1, 9700 RB, Groningen, The Netherlands, ${ }^{4}$ Instituto de Anatomía, Histologíca y Patología Facultad de Medicina, Universidad Austral de Chile, Valdivia, Chile, ${ }^{5}$ Department of Radiology, University Medical Center, University of Groningen, Hanzeplein 1, 9700 RB, Groningen, The Netherlands and ${ }^{6}$ Department of Pediatrics, University Medical Center, University of Groningen, Hanzeplein 1, 9700 RB, Groningen, The Netherlands

Email: Olga A de Wit - olgadewit@hotmail.com; Wilfred FA den Dunnen - w.f.a.den.dunnen@path.umcg.nl; Krystyne M Sollie - k.m.sollie@og.umcg.nl; Rosa Iris Muñoz - imunoz@uach.cl; Linda C Meiners - l.c.meiners@rad.umcg.nl; Oebele F Brouwer - o.f.brouwer@neuro.umcg.nl; Esteban M Rodríguez - erodrigu@uach.cl; Deborah A Sival* - d.a.sival@bkk.umcg.nl

* Corresponding author
\end{abstract}

Published: I March 2008

Cerebrospinal Fluid Research 2008, 5:4 doi:10.1186/1743-8454-5-4
Received: 7 November 2007

Accepted: I March 2008

This article is available from: http://www.cerebrospinalfluidresearch.com/content/5///4

(c) 2008 de Wit et al; licensee BioMed Central Ltd.

This is an Open Access article distributed under the terms of the Creative Commons Attribution License (http://creativecommons.org/licenses/by/2.0), which permits unrestricted use, distribution, and reproduction in any medium, provided the original work is properly cited.

\begin{abstract}
Background: Fetal spina bifida aperta (SBA) is characterized by a spinal meningomyelocele (MMC) and associated with cerebral pathology, such as hydrocephalus and Chiari II malformation. In various animal models, it has been suggested that a loss of ventricular lining (neuroepithelial/ependymal denudation) may trigger cerebral pathology. In fetuses with MMC, little is known about neuroepithelial/ependymal denudation and the initiating pathological events.
\end{abstract}

The objective of this study was to investigate whether neuroepithelial/ependymal denudation occurs in human fetuses and neonates with MMC, and if so, whether it is associated with the onset of hydrocephalus.

Methods: Seven fetuses and I neonate ( $16-40$ week gestational age, GA) with MMC and 6 fetuses with normal cerebral development (22-4I week GA) were included in the study. Identification of fetal MMC and clinical surveillance of fetal head circumference and ventricular width was performed by ultrasound (US). After birth, MMC was confirmed by histology. We characterized hydrocephalus by increased head circumference in association with ventriculomegaly. The median time interval between fetal cerebral ultrasound and fixing tissue for histology was four days.

Results: At 16 weeks GA, we observed neuroepithelial/ependymal denudation in the aqueduct and telencephalon together with sub-cortical heterotopias in absence of hydrocephalus and/or Chiari II malformation. At 2I-34 weeks GA, we observed concurrence of aqueductal neuroepithelial/ependymal denudation and progenitor cell loss with the Chiari II malformation, whereas hydrocephalus was absent. At 37-40 weeks GA, neuroepithelial/ependymal denudation coincided with Chiari II malformation and hydrocephalus. Sub-arachnoidal fibrosis at the convexity was absent in all fetuses but present in the neonate.

Conclusion: In fetal SBA, neuroepithelial/ependymal denudation in the telencephalon and the aqueduct can occur before Chiari Il malformation and/or hydrocephalus. Since denuded areas cannot re-establish cell function, neuro-developmental consequences could induce permanent cerebral pathology. 


\section{Background}

Spina bifida aperta (SBA) is associated with cerebral pathology, such as hydrocephalus, Chiari II malformation, heterotopias and cortical abnormalities [1-3]. In SBA, ventriculomegaly of the posterior horns (i.e. colpocephaly) is already present during fetal life. Because of open communication between the posterior and frontal horns, colpocephaly must reflect an ex vacuo phenomenon. However, during the first weeks after birth, highpressure hydrocephalus is present in the majority of SBA neonates. Little is known about the pathogenesis of these cerebral abnormalities.

According to various animal models, loss of neuroepithelial/ependymal cells is associated with hydrocephalus $[4,5]$. Analogous to these observations in laboratory animals, Sarnat reported presence of ependymal denudation in human hydrocephalic infants [6]. In these hydrocephalic infants, a positive relationship between the amount of ventricular distension and the area of ependymal denudation was indicated [6]. In accordance with Sarnat, Domínguez-Pinos et al. reported presence of ependymal denudation in fetuses with mild communicating hydrocephalus of various origins [7]. However, these fetuses did not show a positive relationship between ventricular dilatation and ependymal denudation [7]. In fetal SBA, information on a potential relationship between hydrocephalus and ependymal denudation is still lacking. Since prenatal surgical closure of the MMC can prevent hydrocephalus and Chiari II malformation [8], insight into such a relationship would be clinically relevant. If hydrocephalus triggers neuroepithelial/ependymal denudation, prevention of hydrocephalus could attenuate loss of neuroepithelial and ependymal cells. Alternatively, neuroepithelial/ependymal denudation and hydrocephalus could share a common etiology. This may involve a primary alteration of the neuroepithelium or ependyma before the initiation of hydrocephalus, as described in hyh mutant mice [9]. In such animal models, the process of neuroepithelial/ependymal denudation is associated with other pathology, such as: abnormalities of junction proteins, abnormal migration of disassembled ependymal cells (into the ventricle and neuropil; i.e. ependymal rosettes), and arrival of numerous macrophages at the site of denudation $[4,10,11]$. If analogous pathological sequences are involved in human fetuses with MMC, prenatal treatment of hydrocephalus would not prevent neuroepithelial/ependymal denudation. In this respect, investigation of the association between neuroepithelial/ ependymal abnormalities and fetal ultrasound (US) measurements (ventriculomegaly/hydrocephaly) may provide new therapeutic insight.

In the present study, we hypothesize that neuroepithelial/ ependymal denudation can be initiated before hydro- cephalus. If so, this would implicate that both abnormalities can share a common etiology rather than the former being a consequence of the latter. Hence, in this study, we associated longitudinal ultrasound (US) parameters for hydrocephalus with the occurrence of neuroepithelial/ ependymal denudation.

\section{Methods \\ Patients}

We retrospectively investigated histological sections of eight MMC patients ( 7 fetuses and 1 neonate) and six fetal controls (collected over the last 15 years at the University Medical Center Groningen). Fetal GA varied from 16-40 weeks. Parents had given informed consent. The medical ethical committee (UMCG, Netherlands) approved retrospective data collection.

In one patient, delivery was caused by abruptio placentae. In the other cases, delivery was induced (prostaglandineE2 medication; $\mathrm{n}=4$ ) and/or assisted (cephalocentesis; $\mathrm{n}$ $=2$ or vacuum extraction; $\mathrm{n}=1$ ). After initiation of delivery, birth occurred the same day (median 12 hours; Table 1). All, except one patient (case 7), died during delivery. Case 7 died during the first postnatal week. Fetal controls $(\mathrm{n}=6)$ varied from 22 to 41 weeks GA. Control fetuses had died from: Potter syndrome, bacteraemia, premature labour, maternal diabetes, umbilical cord strangulation, and complicated twin pregnancy. In control fetuses, delivery was initiated spontaneously $(n=4)$, by caesarean section $(\mathrm{n}=1)$ or induced by prostaglandine-E2 medication $(n=1)$. In all control fetuses, cerebral malformations were absent.

\section{Fetal cerebral ultrasound assessments}

Identification of fetal MMC and clinical surveillance of fetal head circumference and ventricular width was performed by US. After birth, MMC was confirmed by histology and serial fetal US assessments were retrospectively studied with special interest in cerebellar growth and localization, ventriculomegaly, macrocephaly (head circumference > 2 SD) and hydrocephalus (macrocephaly in association with ventriculomegaly) [12-15]. Gestational age during US assessment varied from 21-39 weeks. Time between fetal cerebral US assessment and post mortem fixation was four days (median duration). The neonate was assessed by magnetic resonance imaging (MRI) at postnatal day 3.

\section{Histological preparation}

Histological preparations in fetal MMC and controls involved identical procedures. In both groups, post-mortem time before fixation ranged from $2 \mathrm{~h}$ (most cases) to 3 days. The brain and spinal cord were fixed by immersion in $4 \%$ formalin in phosphate buffered saline ( $\mathrm{pH} \mathrm{7.4).}$ $\mathrm{NaCl}$ was added to the fixative to make the tissue float in 
Table I: Clinical data

\begin{tabular}{|c|c|c|c|c|c|c|c|}
\hline \multirow[t]{2}{*}{ Case } & \multirow[t]{2}{*}{ GA } & \multirow[t]{2}{*}{$M M C$} & \multicolumn{2}{|c|}{ Malformations } & \multirow[t]{2}{*}{ Delivery induction } & \multirow{2}{*}{$\begin{array}{c}\text { Time } \\
\text { induction-delivery }\end{array}$} & \multirow[t]{2}{*}{ Recent acute bleedings } \\
\hline & & & cerebrala $^{\mathrm{a}}$ & non-CNS & & & \\
\hline 1 & 16 & C-Th & $\begin{array}{l}\text { holopros.; fused basal } \\
\text { ganglia; cortical dysplasia }\end{array}$ & $\begin{array}{l}\text { palatoschisis annular } \\
\text { pancreas atresia ani } \\
\text { scoliose }\end{array}$ & PG & $<$ I day & PF \\
\hline 2 & 21 & L-S & - & $\begin{array}{l}\text { reduction defect of } \\
\text { extremity }\end{array}$ & PG & $<$ I day & IVH, SAH, PF \\
\hline 3 & 21 & Th-L & - & single umbilical artery & PG & $<$ I day & $\mathrm{IVH}, \mathrm{SAH}$ \\
\hline 4 & 22 & L-S & - & dysplasia costae kyfose & PG & $<0.5$ day & PF \\
\hline 5 & 34 & Th-L & - & $\begin{array}{l}\text { OEIS complex pes } \\
\text { calcaneovalgus lung } \\
\text { hypoplasia kyphosis }\end{array}$ & abruption placentae & ni & IVH \\
\hline 6 & 37 & L-S & - & - & cephalocentesis & $<$ I day & $\mathrm{IVH}, \mathrm{SAH}, \mathrm{PF}$ \\
\hline 7 & 39 & L-S & $\begin{array}{c}\text { agenesis of: cerebellum, } \\
\text { nucleus olivaris inferior, and } \\
\text { pontine nuclei }\end{array}$ & $\begin{array}{l}\text { pes calcaneovalgus finger- } \\
\text { malformation }\end{array}$ & VE & ni & IVH, PF \\
\hline 8 & 40 & Th-L & hypoplasia of cerebellum & $\begin{array}{l}\text { palatoschisis pes } \\
\text { calcaneovalgus ASD }\end{array}$ & cephalocentesis & $<$ I day & $\mathrm{IVH}, \mathrm{SAH}$ \\
\hline
\end{tabular}

Legends: $\mathrm{GA}=$ gestational age in weeks, $\mathrm{MMC}=$ segmental level of the meningomyelocele, ${ }^{\mathrm{a}}$ cerebral malformations other than ventriculomegaly and Chiari malformation, holopros. = holoprosencephaly, non-CNS = outside the central nervous system, $\mathrm{C}=$ cervical, $\mathrm{Th}=$ thoracal, $\mathrm{L}=$ lumbar, $S=$ sacral, - = absent, OEIS complex = Omphalocele, Exstrophy, Imperforate anus, Spinal defects, ASD = atrium septum defect, PG = prostaglandin, $\mathrm{VE}=$ vacuum extraction, Time induction-delivery $=$ time between induction and delivery, $\mathrm{ni}=$ no induction, $\mathrm{PF}=\mathrm{fossa}$ posterior, IVH $=$ intraventricular bleeding, $\mathrm{SAH}=$ subarachnoidal hemorrhage.

order to overcome deformities during the fixation period of 2 weeks. Paraffin embedded tissue blocks were sectioned at $5 \mu \mathrm{m}$ thickness. The spinal cord, brainstem, and cerebellum were sectioned transversely; the cerebrum was sectioned coronally. Several sections were obtained from blocks containing parts of cortex (8/8 patients), basal ganglia and thalamus $(7 / 8$; case 5 excluded $)$, cerebellum $(8 /$ $8)$, germinal matrix $(8 / 8)$, aqueduct $(7 / 8$; case 5 excluded) and $4^{\text {th }}$ ventricle $(7 / 8$; case 1 excluded $)$ and stained with haematoxylin-eosin.

In addition, tissue blocks containing samples of the cerebral aqueduct $(7 / 8$; case 5 excluded) were serially cut throughout. From several hundred sections per block, 10 representative series were obtained. We therefore mounted every $20^{\text {th }}$ section on a slide, resulting in a series derived from the whole block. In total, this procedure was performed ten times (i.e. for example for the first series: $1^{\text {st }}, 21^{\text {st }}, 41^{\text {st }}$ section and so on; for the second series: $2^{\text {nd }}$, $22^{\text {nd }}, 42^{\text {nd }}$ section and so on), resulting in ten series. Each series was stained by different histochemical and immunocytochemical procedures allowing mutual comparison.

From a theoretical point of view, absence of ependyma could be caused by ependymal denudation or by an artifact (such as by poor fixation, when the post mortem interval is prolonged). In order to discern between the two, we characterized "neuroepithelial/ependymal denudation" as presence of an astroglial reaction (demonstrated by
anti-GFAP) confined to the area of neuroepithelial/ ependymal denudation. Deformities of the aqueduct were assessed as slit like (i.e. luminal narrowing) and forking (i.e. infolding lined by ependymal cells [16]).

\section{Immunocytochemistry}

The following antibodies were used: (1) anti-nestin, raised in rabbit (Santa Cruz Biotechnology, INC., San Diego, CA, USA), 1:100 dilution. During embryogenesis, nestin is an intermediate filament protein, expressed in neuro-epithelial progenitor cells [17]. Incubation was for $60 \mathrm{~min}$, after antigen retrieval using Tris/ $\mathrm{HCl}$, at $\mathrm{pH} 9.0$. Secondary (GaMIgG ${ }_{1}$ bio, DAKO, Glostrup, Denmark) and tertiary (Avidin-Biotin complex, DAKO, Glostrup, Denmark) antibodies were used at 1:750 and 1:100 dilution, respectively, for $30 \mathrm{~min}$; (2) anti-glial fibrillary acidic protein (GFAP), raised in rabbit (Santa Cruz Biotechnology, INC., San Diego, CA, USA), 1:1000 dilution; (3) anticaveolin-1 (neuroepithelial/ependymal marker [18] raised in rabbit, affinity purified (Santa Cruz Biotechnology, INC., San Diego, CA, USA), 1:2000 dilution. Incubation for antibodies 2 and 3 was in a moist chamber for 18 h. Anti-rabbit IgG raised in goat (Sigma, Madrid, Spain) was used at a dilution 1:50 for $1 \mathrm{~h}$. Rabbit PAP (Dako, Carpinteria, CA, USA) was used a 1:75 dilution for 30 min. 3.3'-diaminobenzidine tetrahydrochloride (DAB, Sigma, Madrid, Spain) was used as electron donor. Primary and secondary antibodies were diluted in $0.01 \mathrm{M}$ buffered phosphate saline, $\mathrm{pH} 7.3$, containing $0.1 \%$ 
sodium azide and $0.5 \%$ Triton $\mathrm{X}-100$. Omission of incubation in the primary antibody was used as a control for the immunoreaction.

\section{Results}

The cranial border of the MMC was located at cervical (n $=1)$, thoracic $(\mathrm{n}=3)$ or lumbar $(\mathrm{n}=4)$ segmental levels. One fetus was diagnosed with OEIS complex (omphalocele, exstrophy, imperforate anus, spinal defects; case 5). Malformations other than ventriculomegaly and Chiari II malformation are presented in Table 1.

\section{Fetal cerebral US assessments (Table 2)}

In case one, a fetus of 16 weeks GA, there were no signs of ventriculomegaly or Chiari II malformation. In fetuses of 21-22 weeks GA (3 fetuses), signs of Chiari II malformation (3/3) and ventriculomegaly (1/3) were present. In fetuses of 37-40 weeks GA (3 fetuses), hydrocephalus (2/ $3)$ became additionally present. In the fetus with OEIS complex (case 5; 34 weeks GA), ventriculomegaly and Chiari II malformation were absent.

\section{Neonatal MRI assessment}

In the neonate (case 7, 39 weeks GA) that lived for the first postnatal week, neonatal MRI was performed at day 3. In this case, the MRI indicated absence of the cerebellum, a small brainstem and a prominent cisterna magna. This malformation is also referred to as Chiari IV malformation [19], Table 2. At day 3, MRI did not reflect signs for high intracranial pressure (such as signs of trans-ependymal CSF leakage on T2 weighted images or compression of peripheral CSF spaces).

\section{Histological findings \\ Cerebral aqueduct}

The cerebral aqueduct of young fetuses $(21,21$ weeks GA) was lined by a multilayered neuroepithelium whereas the aqueduct of older fetuses $(27,39$ and 40 weeks GA) was lined by immature ependyma. Both neuroepithelium and ependyma reacted strongly with anti-caveolin (Fig. 1A). In six of eight fetuses (16-40 weeks GA), neuroepithelial/ ependymal denudation (characterized by astrogliosis) was present (Figs. 1A-C). The denuded area ranged from a few ependymal cells up to a few millimeters in length (Figs. 1A-C, 2D, 3A). Several denuded areas could be found throughout the series of sections of the aqueduct. The number of denuded areas varied between cases. Additionally, histological signs for hemosiderophagocytosis were present (3/6) (Fig. 2D). In five cases, sections of the aqueduct were complete for morphological assessment. In these cases, ependymal denudation concurred with malformations of the aqueduct (such as forking (4/5), slit-like deformities $(2 / 5)$ and sub-ependymal rosette formation (cases 6 and 8, 37-40 weeks GA), see Figs. 2A-E, $3 \mathrm{~A}$.

\section{Telencephalon}

At the telencephalon, neuroepithelial/ependymal denudation seemed associated with sub-ventricular heterotopias (16 week GA, Fig. 3B).

The individual relationship between US findings and histological assessments is indicated in Table 2. In all control fetuses, this pathology (ependymal denudation, sub-ventricular heterotopias, gliosis and deformities) was absent.

\section{Cerebral hemorrhage}

In all SBA fetuses, recent delivery-related cerebral bleedings were indicated by the presence of numerous (fresh) erythrocytes. These hemorrhages were observed at intraventricular (6/7), sub-arachnoidal (4/7) and intra-parenchymal locations (Table I). In the available histological preparations of the convexity, sub-arachnoidal fibrosis was absent from all succumbed SBA fetuses $(n=7)$, whereas it was present in the neonate that survived for the first postnatal week (case 7). The time relationship between histological and radiological assessments in SBA patients is shown in figure 4 . In control fetuses, recent cerebral hemorrhage was present in two out of six fetuses, and sub-arachnoidal fibrosis was absent.

Table 2: Relation between cerebral malformations and hydrocephalus

\begin{tabular}{|c|c|c|c|c|c|c|c|c|}
\hline Case & GA & ED & $\mathrm{V}$ & $h c>2$ & $\mathrm{HC}$ & Chiari II & HemoP/Gliosis & Morphologic alteration aqueduct \\
\hline I & 16 & + & - & - & - & - & 【 & П \\
\hline 2 & 21 & + & - & - & - & + & + & $f$ \\
\hline 3 & 21 & - & - & - & - & + & ף & П \\
\hline 4 & 22 & + & + & - & - & + & + & $\mathrm{s}$ \\
\hline 5 & 34 & - & - & - & - & - & T & T \\
\hline 6 & 37 & + & + & + & + & + & + & $f$ \\
\hline 7 & 39 & + & - & - & - & IV & + & $f$ \\
\hline 8 & 40 & + & + & + & + & + & + & $f ; s$ \\
\hline
\end{tabular}

Legends: $\mathrm{GA}=$ gestational age in weeks, $\mathrm{ED}=$ signs of ependymal denudation at the aqueduct or cranial border of the aqueduct, $\mathrm{V}=$ ventriculomegaly, $h c=$ head circumference, $\mathrm{HC}=$ hydrocephalus, Chiari II = Chiari II malformation, HemoP $=$ hemosiderophagocytosis, $+=$ present, - = absent, IV = Chiari IV malformation (absence of the cerebellum), $\mathbb{\|}=$ serial sections at the aqueduct incomplete, $\mathrm{f}=\mathrm{forking}, \mathrm{s}=$ slit like. 


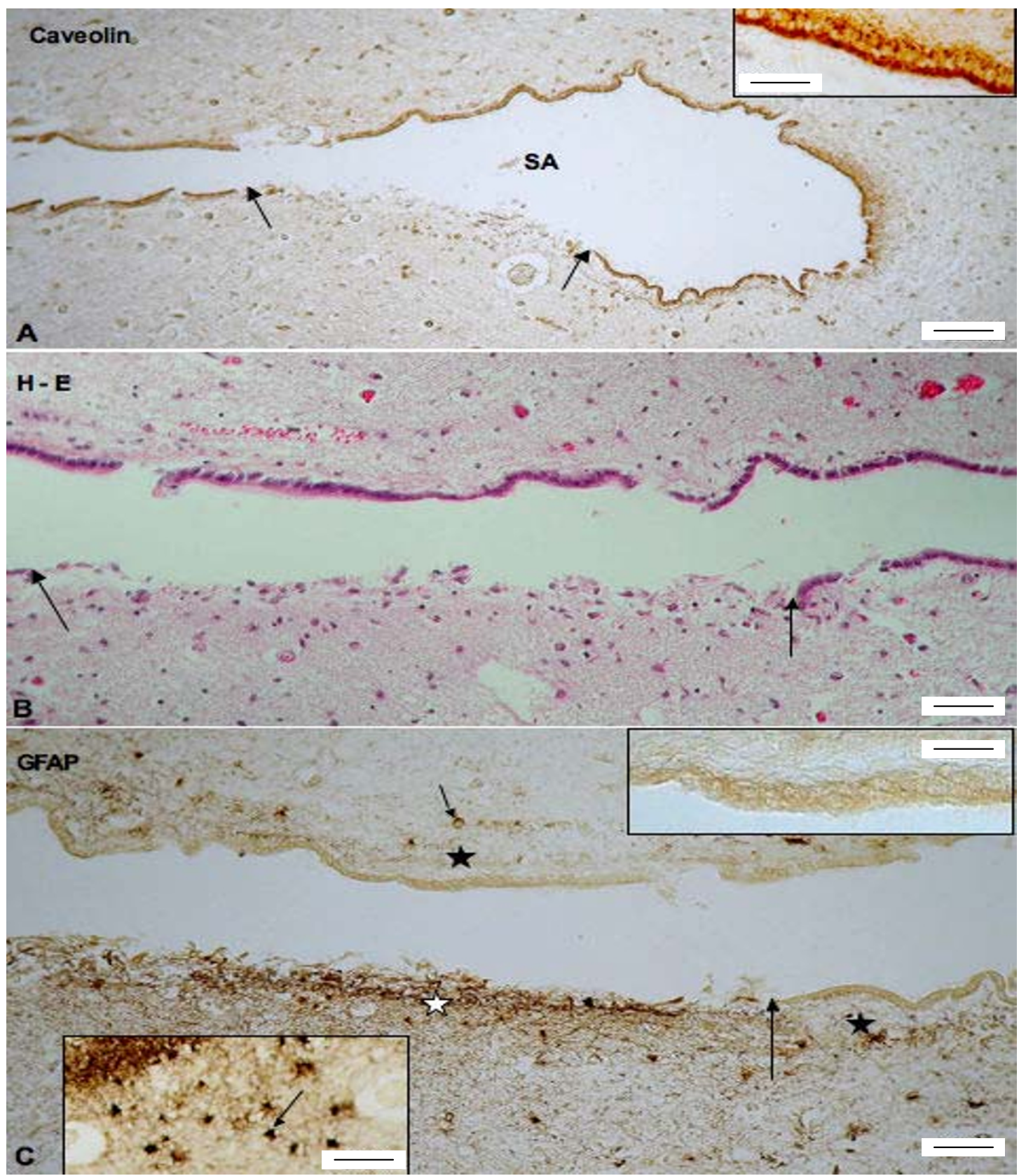

\section{Figure I}

Ependymal denudation and secondary astroglial reaction at the aqueduct of a fetus with MMC (39 weeks GA). A. Transverse section through the aqueduct with immunostaining for caveolin. The ependymal cells are strongly reactive. Arrows indicate an area devoid of ependyma. SA = aqueduct of Sylvius. Scale bar $=100 \mu \mathrm{m}$. Insert: Detailed magnification of immature ependyma immunoreacting with anti-caveolin. Scale bar $=20 \mu \mathrm{m}$. B. Section adjacent to that of previous figure, stained with haematoxylin-eosin. Arrows indicate an area devoid of ependyma. Scale bar $=50 \mu \mathrm{m}$. C. Section adjacent to that of previous figure immunostained with anti-GFAP. Immunoreactive cell processes and cells (astrocytes) are confined to the denuded area (white star). Subependymal neuropil of adjacent areas lined by ependymal cells has only few astrocytes (small arrow) and virtually no astrocyte processes (black stars). The large arrow points to the border of the denuded area. Scale bar $=50 \mu \mathrm{m}$. Top insert: Detailed magnification of the non-reactive ependymal and subependymal neuropil. Scale bar $=30 \mu \mathrm{m}$. Bottom insert: numerous astrocytes (arrow) in the vicinity of the denuded area. Scale bar $=35 \mu \mathrm{m}$. 

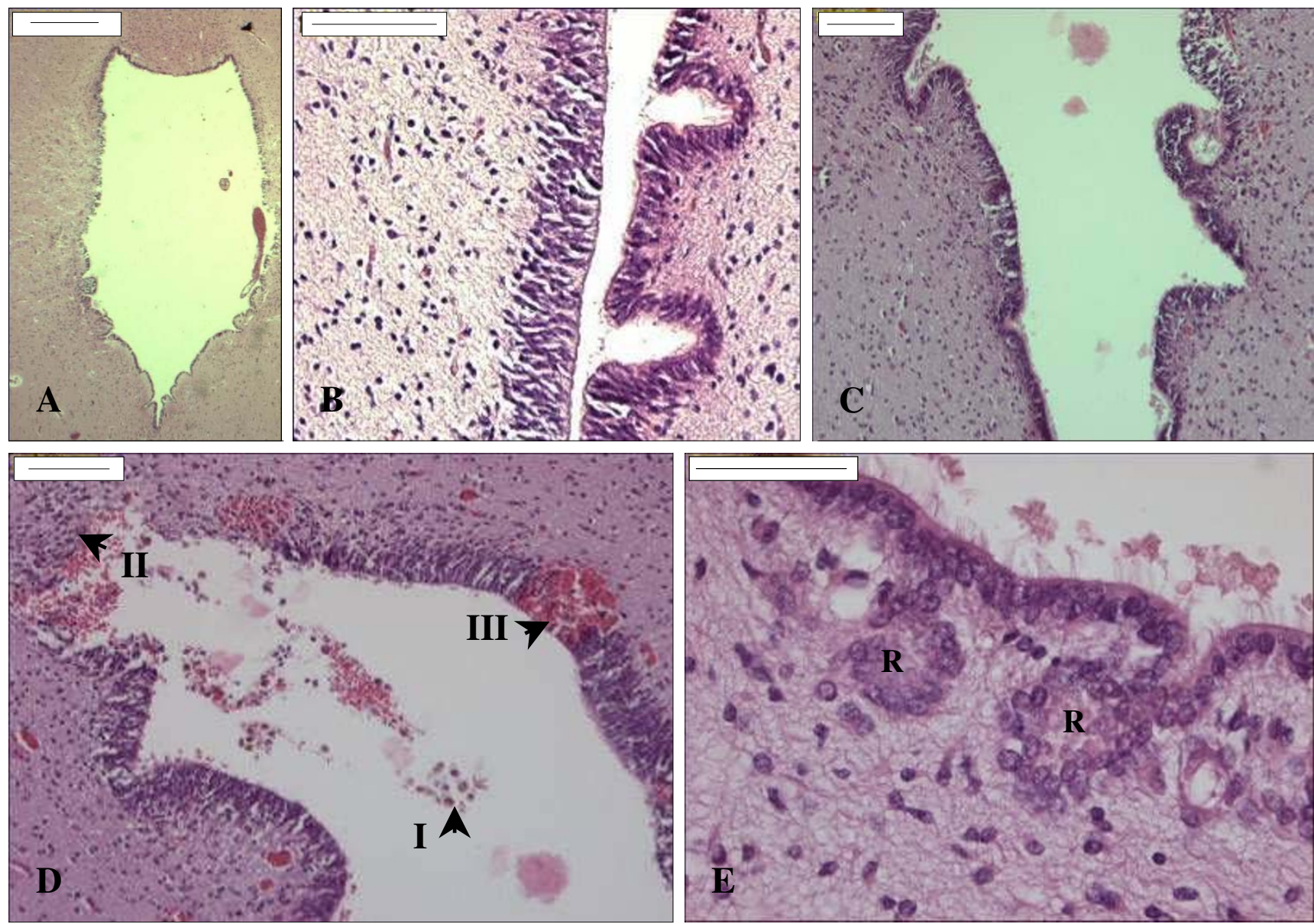

\section{Figure 2}

Haematoxylin-eosin staining of the aqueduct throughout gestation. A. Transverse section through a wide-open aqueduct of a control fetus (40 weeks GA). Scale bar $=500 \mu \mathrm{m}$. B. Transverse section through the aqueduct of a fetus with MMC (22 weeks GA). The lumen appears narrow or slit like. Scale bar $=100 \mu \mathrm{m}$. C. Transverse section through the aqueduct of a fetus with MMC ( 2 I weeks GA). Several infoldings are present (i.e. forking). Scale bar $=100 \mu \mathrm{m}$. D. Secondary damage at the aqueduct of a fetus with MMC (2I weeks GA). Arrowheads indicate haemosiderophages (I), gliosis (II), and recent bleeding (III). Scale bar $=100 \mu \mathrm{m}$. E. Transverse section through the aqueduct of a fetus with MMC (37 weeks GA). The figure shows sub-ventricular rosette formation $(\mathrm{R})$. Scale bar $=50 \mu \mathrm{m}$.

The study also included parts of basal ganglia/thalamus, cerebellum and $4^{\text {th }}$ ventricle (in $7 / 8,8 / 8$ and $7 / 8$ cases; respectively). Neuro-pathological findings at these regions were: abnormal fusion or hemorrhages at basal ganglia/thalamus (cases 1 and 7, respectively); cerebellar a- or hypoplasia (cases 7 and 8, respectively) and hemorrhages in the $4^{\text {th }}$ ventricle (cases $2,3,5,6$ and 8 ). In case 3 , there was a hemorrhage at the choroid plexus.

\section{Discussion}

In perinatal SBA, we associated the initiation of cerebral pathology with the concurrence of neuroepithelial/ ependymal denudation at the aqueduct. In contrast to the controls, fetuses with MMC displayed neuroepithelial/ ependymal denudation at the aqueduct. Our data indicate that neuroepithelial/ependymal denudation may precede hydrocephalus and Chiari II malformation.

Most ependymal cell lineages are born and mature at fixed stages of fetal development $[5,20]$. After closure of the neural tube, choroid plexus villi start to produce cerebrospinal fluid (CSF) [21]. Studies in animal models and humans have shown that this CSF contains essential molecules for neural proliferation and migration [22-27], which is predominantly secreted by choroid plexus and sub-commissural organ [28]. Additionally, fetal ependymal cells can release molecules via their long basal ependymal processes that extend into germinal matrix and white matter. These processes may have a trophic function and provide axonal guidance [5]. Once secreted into CSF, 

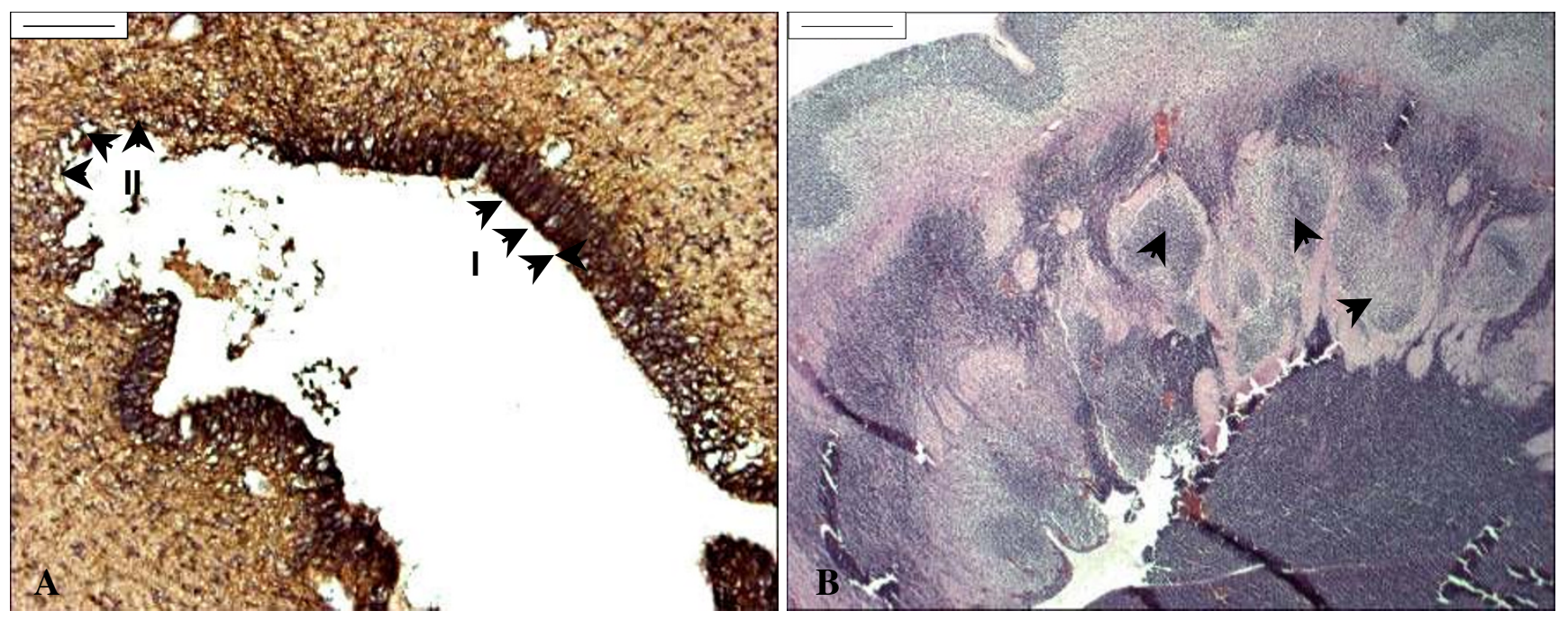

Figure 3

Ependymal denudation and subcortical heterotopias. A. Nestin staining of the aqueduct of a SBA fetus of 2 I weeks GA. Arrowheads indicate intact (I) and denuded (II) ependymal lining. At the denuded area, the figure shows reduction of nestinpositive cells (brown; DAB) indicative of progenitor cell loss. Scale bar $=100 \mu \mathrm{m}$. B. Haematoxylin-eosin staining of the telencephalon of a fetus with MMC (I 6 weeks GA). Arrowheads indicate subcortical heterotopias associated with ependymal denudation of the lateral ventricle. Scale bar $=500 \mu \mathrm{m}$.

molecules follow the CSF flow, reach distant subventricular zones and, through the subarachnoidal space, the external surface of the developing cerebral cortex [28,29]. This CSF flow is maintained by hydrostatic pressure, arte- rial pulsations and beating of ependymal cilia [30,31]. When ependymal cells are damaged, functional restoration does not occur [20]. In a previous study, we have indicated that CSF growth factor concentrations (TGF- $\beta$ )

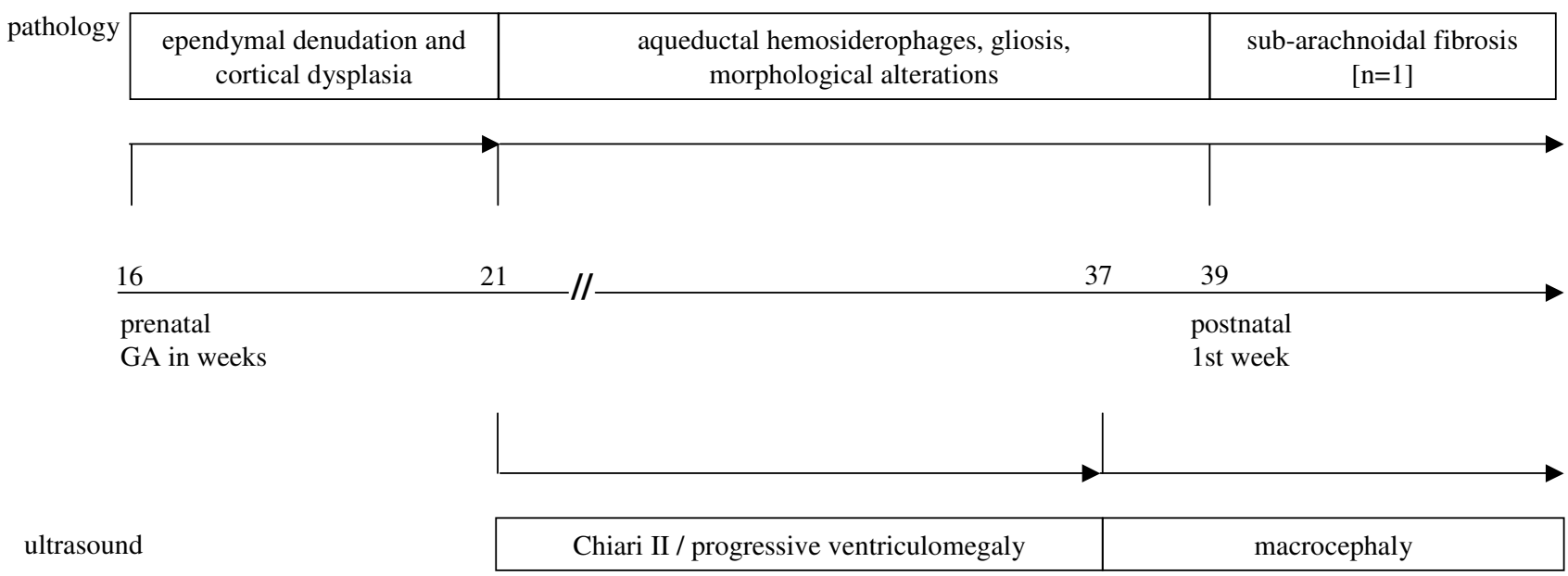

\section{Figure 4}

Histological and ultrasound data in pre- and postnatal SBA according to gestational age. Histological and US findings are illustrated in chronological order, according to gestational (GA). The time axis is in the middle part of the figure. Histological data of aqueduct and convexity are indicated at the upper part of the figure. US data of ventricular size (Chiari II malformation, ventriculomegaly and macrocephaly) are indicated at the lower part of the figure. During the first half of gestation, neuroepithelial/ependymal denudation is observed before the onset of Chiari II malformation and hydrocephalus. 
are comparatively low in neonatal hydrocephalic SBA [27]. Additionally, other proteins (such as vimentin) appear over-expressed in Chiari II malformation and aqueduct stenosis $[32,33]$. These altered concentrations of signaling molecules may influence cerebral development [3].

In fetuses with communicating hydrocephalus, ependymal denudation and/or damage has been described as a consequence of ventricular distension (hydrocephalus) [6]. If such a causative relationship also exists in fetuses with $\mathrm{MMC}$, closure of the MMC may prevent both hydrocephalus and the negative consequences of ependymal denudation. However, our present data indicate that neuroepithelial/ependymal denudation can occur before the onset of hydrocephalus. This is in agreement with the concurrence of ependymal denudation with neural migration disorders in absence of hydrocephalus (i.e. lissencephaly and pachygyria) [34].

The presence of neuroepithelial/ependymal denudation implies loss of progenitor cells. A likely fate of these cells is the CSF, as suggested by findings in human hydrocephalic fetuses [7] and human fetuses with MMC [35]. In accordance with cellular loss into CSF, it has been shown that progenitor cells can be harvested from CSF in preterm hydrocephalic infants [36]. As a consequence, neural proliferation, migration [37] and corticogenesis [5] may be consecutively impaired. Accordingly, we observed cellular heterotopias and abnormal neural migration (at the germinal matrix, $\mathrm{n}=1$, and cortex, $\mathrm{n}=2$ ). For further substantiation, more extensive studies of the lateral ventricles and cerebral cortex of fetuses with MMC are required.

Previous studies have described macrophage invasion and astrogliosis at the denuded areas $[7,10]$. Accordingly, we also observed invasion of macrophages and astrogliosis in human fetal MMC (figures 1, 2, 3, and 4). Subsequent gliosis and scarring of denuded areas may result in aggregates of ependymal cells in the subventricular zone and lead to the formation of subependymal rosettes [5,38-40].

With ongoing gestation, fetal US recordings indicated concurrence of Chiari II malformation and hydrocephalus. Especially during delivery, these malformations are associated with enhanced risk for venous compression (at the large sinuses) and cerebral hemorrhage [41]. In all our patients with MMC, we observed fresh erythrocytes, which suggest recent, delivery-related cerebral hemorrhages. In accordance with a recent onset of these hemorrhages, fetal arachnoidal fibrosis (at the convexity) was absent in all $(\mathrm{n}=7)$ fetuses with $\mathrm{MMC}$, whereas it was present in the neonate with MMC $(\mathrm{n}=1)$. In this patient, clinical history did not reveal another cause for arachnoidal fibrosis. These data may implicate that prenatal pres- ence of progressive ventriculomegaly (and/or hydrocephalus) in fetal SBA is not related to (fibrosisinduced) malabsorption at the convexity.

\section{Conclusion}

The present investigation on human fetal SBA indicates that neuroepithelial/ependymal denudation and abnormal neural migration can occur before the onset of hydrocephalus and Chiari II malformation. Since denuded areas do not re-establish function, fetal SBA surgery is unlikely to prevent these abnormalities.

\section{Abbreviations}

CSF: Cerebrospinal fluid; DAB: Diaminobenzidine substrate; GA: Gestational age; MMC: Meningomyelocele; MRI: Magnetic resonance imaging; SBA: Spina bifida aperta; TGF $\beta-1$ : Transforming growth factor beta-1; US: Ultrasound.

\section{Competing interests}

The authors declare that they have no competing interests.

\section{Authors' contributions}

All authors have read and approved the final version of the manuscript.

OdW: contributed to the study of the sections and preparation of the manuscript.

WdD: contributed to the study design, prepared sections and staining, histological assessments and preparation of the manuscript. KMS: contributed to the collection of the former obstetric assessments and advised during the preparation of the manuscript. RIM: contributed to the serial sections of tissue blocks, immunostaining and interpretation of histological assessments. LM: contributed to radiological assessments and advised during the preparation of the manuscript. OFB: contributed to clinical neurological data collection and advised during the preparation of the manuscript. EMR: contributed to the serial sections of tissue blocks, immunostaining, histological assessments and preparation of the manuscript. DAS: contributed to the study design, histological assessments and preparation of the manuscript.

\section{Acknowledgements}

The authors wish to thank Mrs. Kunst and Mrs. den Dunnen-Briggs for their administrative help and correction of the English grammar. EMR was supported by Grants from Fondecyt 107024I, Chile.

\section{References}

I. Gilbert JN, Jones KL, Rorke LB, Chernoff GF, James HE: Central nervous system anomalies associated with meningomyelocele, hydrocephalus, and the Arnold-Chiari malformation: reappraisal of theories regarding the pathogenesis of posterior neural tube closure defects. Neurosurgery 1986, I 8:559-564.

2. Stein SC, Schut L: Hydrocephalus in myelomeningocele. Childs Brain 1979, 5:413-419. 
3. Miyan J, Sobkowiak C, Draper C: Humanity lost: the cost of cortical maldevelopment. Is there light ahead? Eur J Pediatr Surg 200I, I I(SuppI I):S4-S9.

4. Jimenez AJ, Tome M, Paez P, Wagner C, Rodriguez S, Fernandez-Llebrez P, Rodriguez EM, Perez-Figares JM: A programmed ependymal denudation precedes congenital hydrocephalus in the hyh mutant mouse. J Neuropathol Exp Neurol 200 I, 60: I 105-III9.

5. Sarnat HB: Role of human fetal ependyma. Pediatr Neurol 1992, 8:163-178.

6. Sarnat HB: Ependymal reactions to injury. A review. J Neuropathol Exp Neurol 1995, 54: I-I5.

7. Dominguez-Pinos MD, Paez P, Jimenez AJ, Weil B, Arraez MA, PerezFigares JM, Rodriguez EM: Ependymal denudation and alterations of the subventricular zone occur in human fetuses with a moderate communicating hydrocephalus. J Neuropathol Exp Neurol 2005, 64:595-604.

8. Bruner JP, Tulipan N, Paschall RL, Boehm FH, Walsh WF, Silva SR, Hernanz-Schulman M, Lowe LH, Reed GW: Fetal surgery for myelomeningocele and the incidence of shunt-dependent hydrocephalus. JAMA 1999, 282:1819-1825

9. Paez P, Batiz LF, Roales-Bujan R, Rodriguez-Perez LM, Rodriguez $S$, Jimenez AJ, Rodriguez EM, Perez-Figares JM: Patterned neuropathologic events occurring in hyh congenital hydrocephalic mutant mice. J Neuropathol Exp Neurol 2007, 66:1082-1092.

10. Wagner C, Batiz LF, Rodriguez S, Jimenez AJ, Paez P, Tome M, PerezFigares JM, Rodriguez EM: Cellular mechanisms involved in the stenosis and obliteration of the cerebral aqueduct of hyh mutant mice developing congenital hydrocephalus. J Neuropathol Exp Neurol 2003, 62:1019-1040.

II. Ganzler-Odenthal SI, Redies C: Blocking N-cadherin function disrupts the epithelial structure of differentiating neural tissue in the embryonic chicken brain. J Neurosci 1998, 1 8:5415-5425

12. Cardoza JD, Goldstein RB, Filly RA: Exclusion of fetal ventriculomegaly with a single measurement: the width of the lateral ventricular atrium. Radiology 1988, 169:7| I-7|4.

13. Van den Hof MC, Nicolaides KH, Campbell J, Campbell S: Evaluation of the lemon and banana signs in one hundred thirty fetuses with open spina bifida. Am J Obstet Gynecol 1990, 162:322-327.

14. Bannister CM, Russell SA, Rimmer S, Arora A: Pre-natal ventriculomegaly and hydrocephalus. Neurol Res 2000, 22:37-42.

15. Snijders RJ, Nicolaides KH: Fetal biometry at 14-40 weeks' gestation. Ultrasound Obstet Gynecol 1994, 4:34-48.

16. Kakita A, Takahashi H: Hydrocephalus. In Developmental Neuropathology Edited by: Golden JA, Harding BN. Basel: ISN Neuropath Press; 2004:126-130.

17. Lendahl U, Zimmerman LB, McKay RD: CNS stem cells express a new class of intermediate filament protein. Cell 1990 60:585-595.

18. Peruzzo B, Pastor FE, Blazquez JL, Amat P, Rodriguez EM: Polarized endocytosis and transcytosis in the hypothalamic tanycytes of the rat. Cell Tissue Res 2004, 3 17: I 47-164.

19. Tortori-Donati P, Rossi A, Biancheri R: Brain Malformations. In Pediatric Neuroradiology Edited by: Heilmann U. Heidelberg: Springer Berlin Heidelberg New York; 2005: I7I-198.

20. Sarnat HB: Histochemistry and immunocytochemistry of the developing ependyma and choroid plexus. Microsc Res Tech 1998, 41:14-28.

21. Owen-Lynch PJ, Draper CE, Mashayekhi F, Bannister CM, Miyan JA: Defective cell cycle control underlies abnormal cortical development in the hydrocephalic Texas rat. Brain 2003, 1 26:623-631.

22. Doublier S, Duyckaerts C, Seurin D, Binoux M: Impaired brain development and hydrocephalus in a line of transgenic mice with liver-specific expression of human insulin-like growth factor binding protein-I. Growth Horm IGF Res 2000, 10:267-274.

23. Johnson MD, Gold LI, Moses HL: Evidence for transforming growth factor-beta expression in human leptomeningeal cells and transforming growth factor-beta-like activity in human cerebrospinal fluid. Lab Invest 1992, 67:360-368.

24. Arnold PM, Ma JY, Citron BA, Festoff BW: Insulin-like growth factor binding proteins in cerebrospinal fluid during human development and aging. Biochem Biophys Res Commun 1999, 264:652-656.
25. Montecinos HA, Richter H, Caprile T, Rodriguez EM: Synthesis of transthyretin by the ependymal cells of the subcommissural organ. Cell Tissue Res 2005, 320:487-499.

26. Johanson CE, Preston JE, Chodobski A, Stopa EG, Szmydynger-Chodobska J, McMillan PN: AVP VI receptor-mediated decrease in $\mathrm{Cl}$ - efflux and increase in dark cell number in choroid plexus epithelium. Am J Physiol 1999, 276:C82-C90.

27. Heep A, Bartmann P, Stoffel-Wagner B, Bos A, Hoving E, Brouwer O, Teelken A, Schaller C, Sival D: Cerebrospinal fluid obstruction and malabsorption in human neonatal hydrocephaly. Childs Nerv Syst 2006, 22: 1249-1255.

28. Rodriguez EM: The cerebrospinal fluid as a pathway in neuroendocrine integration. J Endocrinol 1976, $71: 407-443$.

29. Miyan JA, Nabiyouni M, Zendah M: Development of the brain: a vital role for cerebrospinal fluid. Can J Physiol Pharmacol 2003, $81: 317-328$

30. Perez-Figares JM, Jimenez AJ, Rodriguez EM: Subcommissural organ, cerebrospinal fluid circulation, and hydrocephalus. Microsc Res Tech 200I, 52:591-607.

31. Yamadori T, Nara K: The directions of ciliary beat on the wall of the lateral ventricle and the currents of the cerebrospinal fluid in the brain ventricles. Scan Electron Microsc 1979:335-340.

32. Takano T, Rutka JT, Becker LE: Overexpression of nestin and vimentin in ependymal cells in hydrocephalus. Acta Neuropathol 1996, 92:90-97.

33. Sarnat HB: Regional ependymal upregulation of vimentin in Chiari II malformation, aqueductal stenosis, and hydromyelia. Pediatr Dev Pathol 2004, 7:48-60.

34. Sarnat HB, Darwish HZ, Barth PG, Trevenen CL, Pinto A, Kotagal S, Shishikura K, Osawa M, Korobkin R: Ependymal abnormalities in lissencephaly/pachygyria. I Neuropathol Exp Neurol 1993, 52:525-541.

35. Sival DA, Verbeek RJ, Brouwer OF, Sollie KM, Bos AF, den Dunnen WFA: Spinal hemorrhages are associated with early neonatal motor function loss in human spina bifida aperta. Earl Hum Dev 2008.

36. Krueger RC Jr, Wu H, Zandian M, Danielpour M, Kabos P, Yu JS, Sun $Y E$ : Neural progenitors populate the cerebrospinal fluid of preterm patients with hydrocephalus. J Pediatr 2006, 148:337-340.

37. Volpe J]: Overview: normal and abnormal human brain development. Ment Retard Dev Disabil Res Rev 2000, 6:I-5.

38. Baker DW, Vinters HV: Hydrocephalus with cerebral aqueductal dysgenesis and craniofacial anomalies. Acta Neuropathol 1984, 63:170-173.

39. Wippold FJ, Perry A: Neuropathology for the neuroradiologist: rosettes and pseudorosettes. AJNR Am J Neuroradiol 2006, 27:488-492.

40. Wunschmann A, Oglesbee M: Periventricular changes associated with spontaneous canine hydrocephalus. Vet Pathol $200 \mathrm{I}$, 38:67-73.

41. Andeweg J: Intracranial venous pressures, hydrocephalus and effects of cerebrospinal fluid shunts. Childs Nerv Syst 1989, 5:318-323.

Publish with Bio Med Central and every scientist can read your work free of charge

"BioMed Central will be the most significant development for disseminating the results of biomedical research in our lifetime. "

Sir Paul Nurse, Cancer Research UK

Your research papers will be:

- available free of charge to the entire biomedical community

- peer reviewed and published immediately upon acceptance

- cited in PubMed and archived on PubMed Central

- yours - you keep the copyright
BioMedcentral 